\title{
Highly Turbulent Flow Laminarized by Hairy Pipe Walls
}

\author{
Bo Anders Nordell ${ }^{1, *}$, Ragnar Oskar Gawelin ${ }^{2}$ \\ ${ }^{1}$ Department of Architecture and Water, Luleå University of Technology, SE-97187 Luleå, Sweden \\ ${ }^{2}$ Enskilda Gymnasiet, SE-11161 Stockholm, Sweden
}

\section{Email address:}

bon@1tu.se (B. A. Nordell), ragnar.gawelin@enskildagymasiet.se (R. O. Gawelin)

\section{To cite this article:}

Bo Anders Nordell, Ragnar Oskar Gawelin. Highly Turbulent Flow Laminarized by Hairy Pipe Walls. International Journal of Mechanical Engineering and Applications. Vol. 3, No. 4, 2015, pp. 63-70. doi: 10.11648/j.ijmea.20150304.13

\begin{abstract}
Nature has found ways to laminarize turbulent flows, as demonstrated by the high swim speed of dolphins and the silent flight of owls. Owls locate their prey by hearing and need to fly silently. In both cases it has something to do with the soft pliable surface of the moving body and the wavy pattern that occurs on the dolphin skin and the owl feathers. Our objective was to investigate whether a pipe lined with a hairy soft carpet would "laminarize" air flows. The degree of laminarization was determined by the velocity profile. Manual pressure measurements were done to determine the air velocity at cross-sections along the pipe. Varying flow rates were tested before the hair was cut increasingly shorter. It was found that for some hair lengths the velocity profile approached the parabolic form of laminar flow at very high Reynolds number.
\end{abstract}

Keywords: Flows in Pipes and Nozzles, High-Reynolds-number Turbulence, Interactions with Surfaces, Laboratory Studies, Laminarization, Stability of Laminar Flows, Velocity Measurements

\section{Introduction}

Many attempts have been made in reducing turbulence and to laminarize flows in order to influence friction and heat transfer. Reference [1] made experiments on the effects of fluid injection of an initially fully developed, low Reynolds (Re) number (from 3090 to 6350) turbulent pipe flow. They used a porous-walled pipe lined by a Rayon cloth. By injecting air through the porous wall at a $\mathrm{Re} \approx 100$ a local instant laminarization was observed close to the wall. Even in the core region the flow was slightly laminarized. However, in the downstream portion of the porous tube the entire flow undergoes a re-transition to fully developed turbulence. It is also known that accelerated turbulent flows show variations in heat transfer and friction that are interpreted as laminarization of the flow. This laminarization occurs only in the boundary layer close to the pipe wall [2]. Laminarization has also been observed and studied in unsteady turbulent flows [3] and in accelerating open channel flows [4]. The main problem with the different methods to laminarize pipe flows is that they only work locally and that the flow returns back to chaotic flow pattern after some time or distance from the occurrence. A recent literature review shows little or no progress.

However, nature has developed various ways to reduce turbulence or at least the consequences of turbulence. Some examples were looked into as part of current work, e.g. polymer additives for friction reduction in water [5,6], wave pattern in bronchial cilia in the human air ways [7], the silent flight of owls $[8,9,10,11,12]$ and the super-efficient swimming ability of dolphins [13,14].

There are many different types of owl but it is normally a rather big bird that flies at a speed of $20 \mathrm{~m} / \mathrm{s}$. The seemingly soundless flight of owls is necessary as it depends on its hearing to localize its prey [15]. It is generally accepted that its hairy feathers and the softness and pliability of the whole body enable its soundless flight $[10,12]$. The dolphin swims at $15-20 \mathrm{~m} / \mathrm{s}$ and its motion through water has been the subject of numerous studies. In 1938 James Gray found that its maximum muscle power of approximately two horse powers is not in proportion to the high speed at which it can swim. This observation, Gray's paradox, concludes that the power of a dolphin was a factor of ten too small to overcome its drag forces in water [14]. Gray assumed that dolphin skin must have special anti-drag properties. Coustaeu observed that longitudinal folds or patterns occur on the dolphin's skin when it is swimming at high speed [16]. This is partly explained by a fluid fat layer just beneath the dolphin's permeable outer skin. The resilient skin seems to dissolve eddies, thereby reducing friction between the dolphin and the 
water.

So, it seems as if the owl can fly and the dolphin can swim with little or no turbulence. The owl and the dolphin have very soft and resilient surfaces that diminish occurring swirls in air and water. Such soft wavy surfaces seem to unravel occurring eddies.

\section{Objectives}

The main objective was to investigate if the turbulence of an air flow would be reduced by a pressure equalizing pipe wall material. The lining fabric should be soft, hairy and pliable enough to change shape when subjected to the pressure of an eddy. The rate of laminarization was analyzed by the shape of the velocity profile. Current study is based on measurements that were carried out by the authors already in $1979[17,18]$.

\subsection{Method and Test Set-up}

The test setup consisted of a plastic (PVC) pipe, Length $=5.16 \mathrm{~m}$; Diameter $=0.15 \mathrm{~m}$, which was lined with a hairy carpet. The pipe was cut in two half pipes, to make it easier to glue the carpet onto the pipe wall, and then attached back together again, and carefully sealed. The carpet consisted of a $100 \%$ polyester fur fabric (fake fur) with long hair, initially $80 \mathrm{~mm}$. Air was pumped through the pipe while the static and total pressures of the air flow were measured at 15 sections along the pipe. These pressure measurements were made by a Prandtl probe $[17,18]$, vertically and horizontally at each $5 \mathrm{~mm}$ of the diameter, to determine the velocity profile. Since the objective was to study how the velocity profile of the air flow was influenced by the soft walls (the hairy carpet) of the pipe, the hair was cut before a new series of measurements started. Finally only the fabric of the carpet remained.

The total pressure of a flow is the sum of the static pressure and dynamic pressure, i.e. the "wind force" of the flow. Since the latter depends on air density the dry and wet temperature of the air were also measured while the ambient air pressure was obtained from the local weather station. The test equipment used was standard laboratory equipment for studies of ventilation systems and related problems (Fig.1). The air flow rate was determined in the rectangular section $(114 \mathrm{~mm} x$ $126 \mathrm{~mm}$ ), before it reached the entrance to the test pipe, according to the guidelines stated by the Nordic Ventilation Group [19].

\subsection{Theoretical Background}

The theoretical background applied here can be found in introductory books on fluid dynamics see e.g. [20]. The state of a flow is characterized by its Reynolds Number (Re), which for a pipe flow this is given by:

$$
\operatorname{Re}=\frac{\mathrm{u}_{\text {mean }} \cdot \mathrm{D}}{\mathrm{v}}
$$

which is a function of mean flow velocity $\mathrm{u}_{\text {mean }}\left(\mathrm{m} \mathrm{s}^{-1}\right)$, fluid viscosity $v\left(\mathrm{~m}^{2} \mathrm{~s}^{-1}\right)$, and diameter of the pipe $\mathrm{D}(\mathrm{m})$. The size of the dimensionless Re means that the state of the flow is laminar for $\operatorname{Re}<2300$ and turbulent for $\operatorname{Re}>4,000$. In between these values the flow is in an intermediate state where the flow is neither laminar nor turbulent. For even greater Re the flow becomes increasingly turbulent. In laminar pipe flow the fluid velocity is described by a parabolic profile while the turbulent velocity profile is blunter. The laminar flow velocity $u(r)$ is stable while the turbulent is not. The volume flow rate is obtained after integration over the cross sectional area, A.

$$
\mathrm{Q}=\int_{0}^{\mathrm{R}} 2 \pi \cdot \mathrm{r} \cdot \mathrm{u}(\mathrm{r}) \cdot \partial \mathrm{r}=\mathrm{U} \cdot \mathrm{A}
$$

The flow rate $\mathrm{Q}\left(\mathrm{m}^{3} \mathrm{~s}^{-1}\right)$ is for a laminar flow confined by a parabolic curve of height $u_{\max }$, which is the maximum flow velocity.

$$
\mathrm{Q}=\mathrm{A} \frac{\mathrm{u}_{\max }}{2}
$$

In fluid flows three different pressures are defined; total pressure $\left(p_{t}\right)$, static pressure $\left(p_{s}\right)$ and dynamic pressure $\left(p_{d}\right)$. The static pressure is the one that the fluid medium exerts on the pipe wall, perpendicular to the flow direction. The dynamic pressure is the pressure that the fluid is creating in its flow direction, while the sum these two pressures is the total pressure.

$$
p_{t}=p_{d+} p_{s}
$$

The dynamic pressure equals the kinetic energy of a flow divided by its volume, which means that it is the volumetric kinetic energy. So, by starting with the classical equation for kinetic energy $\mathrm{E}$, we get;

$$
\mathrm{E}=\frac{\mathrm{m} \cdot \mathrm{u}^{2}}{2}
$$

Here, $\mathrm{m}$ is mass $(\mathrm{kg}), \mathrm{u}$ is velocity $(\mathrm{m} / \mathrm{s})$ and $\rho$ is density ( $\mathrm{kg} \mathrm{m}-3$ ). Now, by dividing this energy by the volume flow rate $\dot{V}(\mathrm{~m} 3 \mathrm{~s}-1)$ the hydro dynamic pressure (Pd) is given by

$$
\mathrm{p}_{\mathrm{d}}=\frac{\mathrm{E}}{\dot{\mathrm{V}}}=\frac{\mathrm{m} \cdot \mathrm{u}^{2}}{2 \cdot \dot{\mathrm{v}}}=\frac{\rho \cdot \mathrm{u}^{2}}{2}
$$

The pressure drop, i.e. the friction loss, along the pipe was measured for each studied case of flow rate and hair length. In the case of a flow through a straight pipe with constant diameter the pressure drop is given by:

$$
\Delta \mathrm{p}=\frac{\lambda \cdot \mathrm{L} \cdot \mathrm{p}_{\mathrm{d}}}{\mathrm{D}_{\mathrm{h}}} \rightarrow \lambda=\frac{\Delta \mathrm{p} \cdot \mathrm{D}_{\mathrm{h}}}{\mathrm{L} \cdot \mathrm{p}_{\mathrm{d}}}
$$

where $\Delta p=$ pressure drop $(\mathrm{Pa}) ; \lambda=$ friction number $(-) ; \mathrm{L}=$ pipe length $(\mathrm{m}) ; \mathrm{D}_{\mathrm{h}}=$ hydraulic diameter $(\mathrm{m})$;

Performed laboratory studies on turbulence reduction in pipe flow meant that 5600 manual pressure measurements were carried out to determine the flow velocities at different cross 


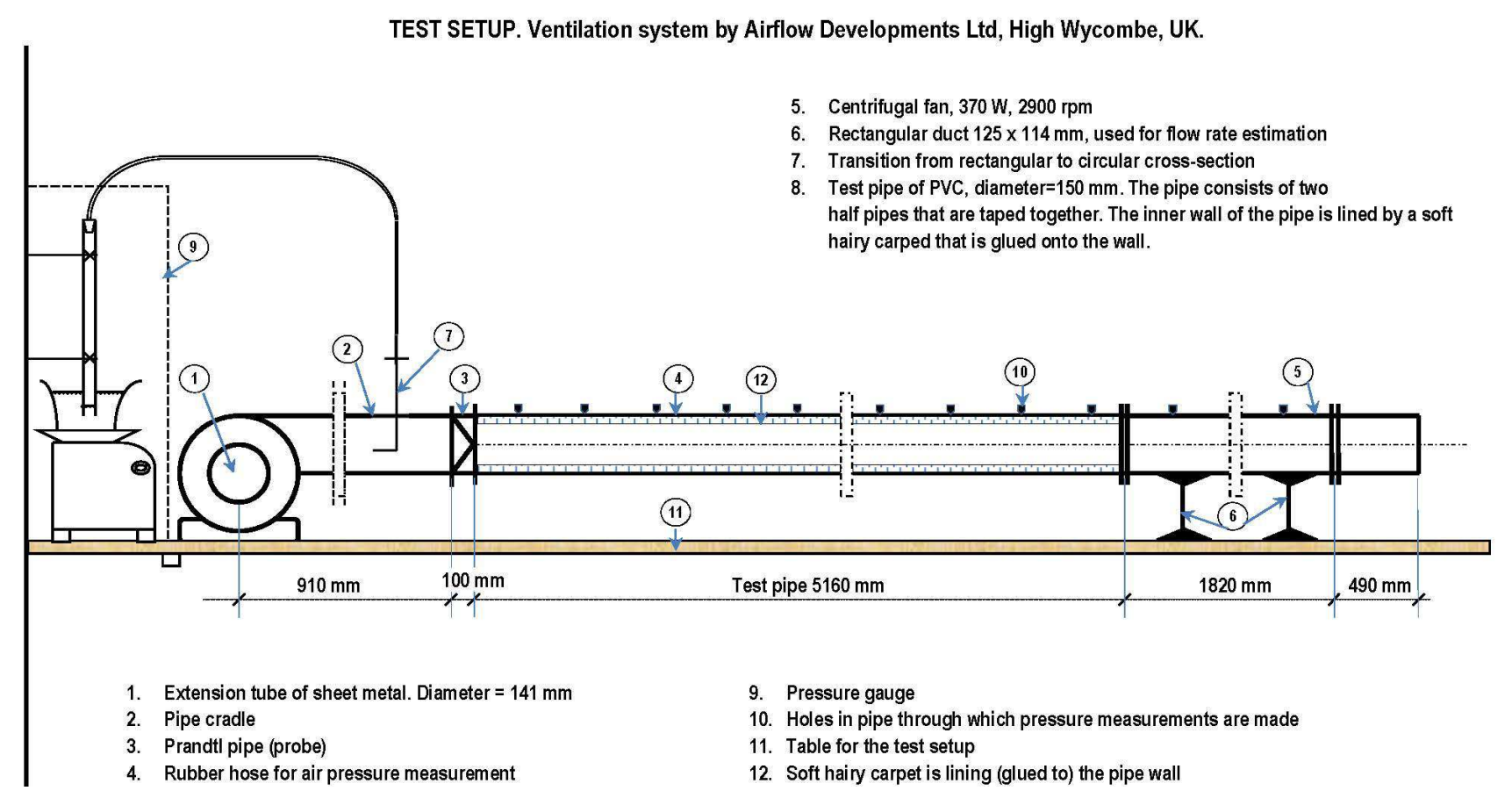

Figure 1. Description of the test setup that was used for the laminarization experiment in 1979 at LTU, Sweden.

sectional areas of the pipe. Further pressure measurements were made in the section before the test pipe in order to determine the flow rate. The measurements were made during May and June 1979 and are available on the Internet [17].

The measured static pressure drops linearly along the test pipe as expected. One notable observation is that this pressure becomes negative for hair lengths greater than 15 $\mathrm{mm}$. The negative static pressure was built up within a few seconds after the start of the air flow.

In performed laboratory test the flow velocity was determined by the dynamic pressure $\left(\mathrm{p}_{\mathrm{d}}\right)$ of the air over cross-sectional areas of the test pipe. In order to do this the total pressure $\left(p_{t}\right)$ and the static pressure $\left(p_{s}\right)$ were measured, and the dynamic pressure was determined by eq. (4).

These measurements were made manually with, at the time, a common method for reliable air pressure measurements.

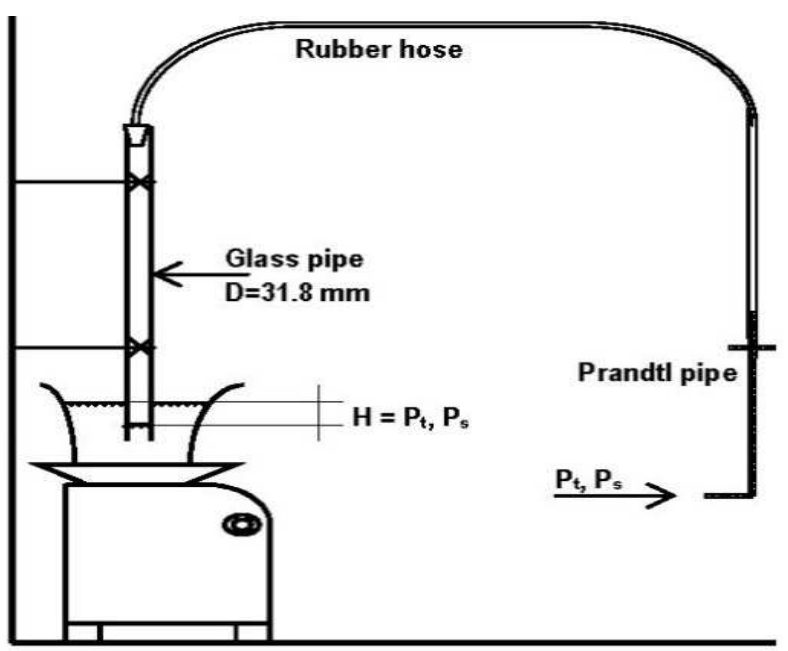

Figure 2. Reliable pressure measurements were obtained by connecting a Prandtl probe to a water-filled vessel placed on an accurate balance.
Actually the air pressure was transferred through a rubber pipe into a glass pipe that was partly submerged into a water filled container. The pressure was then seen as a reduced water level $(\mathrm{H})$ in the glass pipe. Since the water-filled vessel was placed on a balance the mass of the displaced water was measured.

The mass of the displaced water was very accurately measured and a correspondingly accurate pressure was determined, see Fig. 1 and Fig. 2.

$$
p_{d}=\frac{\rho_{a} \cdot u^{2}}{2}=H \rho_{w} g \text { where } H=\frac{m_{d} \cdot 4}{\rho_{w} \cdot \pi d^{2}}
$$

The densities $(\mathrm{kg} \mathrm{m}-3)$ of air and water are denoted $\rho_{\mathrm{a}}$ and $\rho_{\mathrm{w}}$. The gravitational constant is $\mathrm{g}\left(\mathrm{m} \mathrm{s}^{-2}\right)$ and $\mathrm{H}$ is the displaced water i.e. air pressure in $\mathrm{mm}$ water column, see Fig. 2 . The mass of displace water $\left(m_{d}\right)$ is what is measured by the balance and recalculated into dynamic pressure and corresponding air velocity $\mathrm{u}$ is then given by eq. 9 .

\section{Results}

\subsection{Wave Pattern}

A frequent observation in our studies of related flow phenomena was the presence of waves and wave pattern. When a dolphin swims at high velocity its skin vibrates and a wave pattern can be seen on its body. A flying owl has a blurry surface because its body surface, which is very flexible and resilient for vortices, shows a wavy movement. Even the cilia covered bronchial surface shows such wavy patterns. 
Based on these observations we expected to see a wave pattern also occur in the hairy test pipe. In order to investigate possible waves, the carpet was combed before each test run. After each test, the test pipe was opened "for a haircut". It was then observed that the mat was scruffy and disordered at the entrance of the pipe $(\sim 0.2 \mathrm{~m})$, while a soft wave pattern had been formed along the rest of its length. The synthetic carpet retained the property of the waves even after the fan stopped. This pattern was ripple-like with a wave length of $0.1-0.2 \mathrm{~m}$.

\subsection{Friction Loss}

The friction number was determined for the different hair lengths of the wall carpet, Fig 3. It is seen that the friction number was about the same for the $80 \mathrm{~mm}$ and the $50 \mathrm{~mm}$ hair length, and thereafter reduced for each haircut. The friction number is almost constant as a function of flowrate while it increases with increasing hair length. In laminar flows the friction number is $\lambda=64 / \mathrm{Re}$ i.e. the friction reduces linearly with the increasing $\mathrm{Re}$ for $\mathrm{Re}<2500$. However, here with $\operatorname{Re}>50000$, this linear function for laminar flow is not valid.

\subsection{Laminarization of Velocity Profile}

The velocity profile of the pipe air flow was determined for various hair lengths of the wall carpet and for flows with Re between 30,000 and 150,000. In all tests the flow had an obvious turbulent velocity profile at the pipe entrance, which for some hair lengths the profile is almost perfectly laminar was changed along the pipe until it in some cases formed a rotated parabolic shape. Performed measurements show that even at very high Re. The Fig. $4 \mathrm{a}$ and Fig. $4 \mathrm{~b}$ show the air velocity profiles along the pipe at $\operatorname{Re} \sim 60000$ for 8 different hair lengths. Measurements on other Re numbers are documented in [17].

The turbulent velocity profile in the smooth pipe (case 1:4) does not change along the $5 \mathrm{~m}$ test pipe. For the $80 \mathrm{~mm}$ hair length (case 2:4) the shape of the velocity profile is close to laminar at the end of the pipe and for $50 \mathrm{~mm}$ hair length (case 3:4) it is even better. Case 4:4 (25 mm hair length) is not as good as the $50 \mathrm{~mm}$ and $15 \mathrm{~mm}$ hair length (case 5:4). We therefore assume that our measurements were less accurate in case $4: 4$. It has most likely to do with an error in determining the flow rate. For increasingly shorter hair length $(10 \mathrm{~mm}, 2 \mathrm{~mm}$ i.e. case $6: 4$ and case $7: 4)$ the velocity profiles tend to change towards a more turbulent shape. In case 8:4 which means that all hair was removed, the hair was burned away so that only the mat canvas remained, the velocity profile is again fully turbulent.

In Fig. 5 the velocity profiles for the maximum $\mathrm{Re}$ of all eight cases are shown. Here, the profiles for all sections along the pipe are shown in the same diagram to show how the profiles are developing along the pipe. Also the ideal laminar profile is included in all graphs. The hair lengths of $50 \mathrm{~mm}$ and $15 \mathrm{~mm}$ (case 3 and case 5), are very close to laminar velocity profile. The reason why $25 \mathrm{~mm}$ hair is not as close is probably because of some measurement error, maybe in determining the flow rate. It is also obvious that a hair length of $10 \mathrm{~mm}$ or shorter is not able to laminarize the flow. For a hair length of $2 \mathrm{~mm}$ the velocity shows an almost turbulent velocity profile. Measured data and all velocity profiles are available [17].

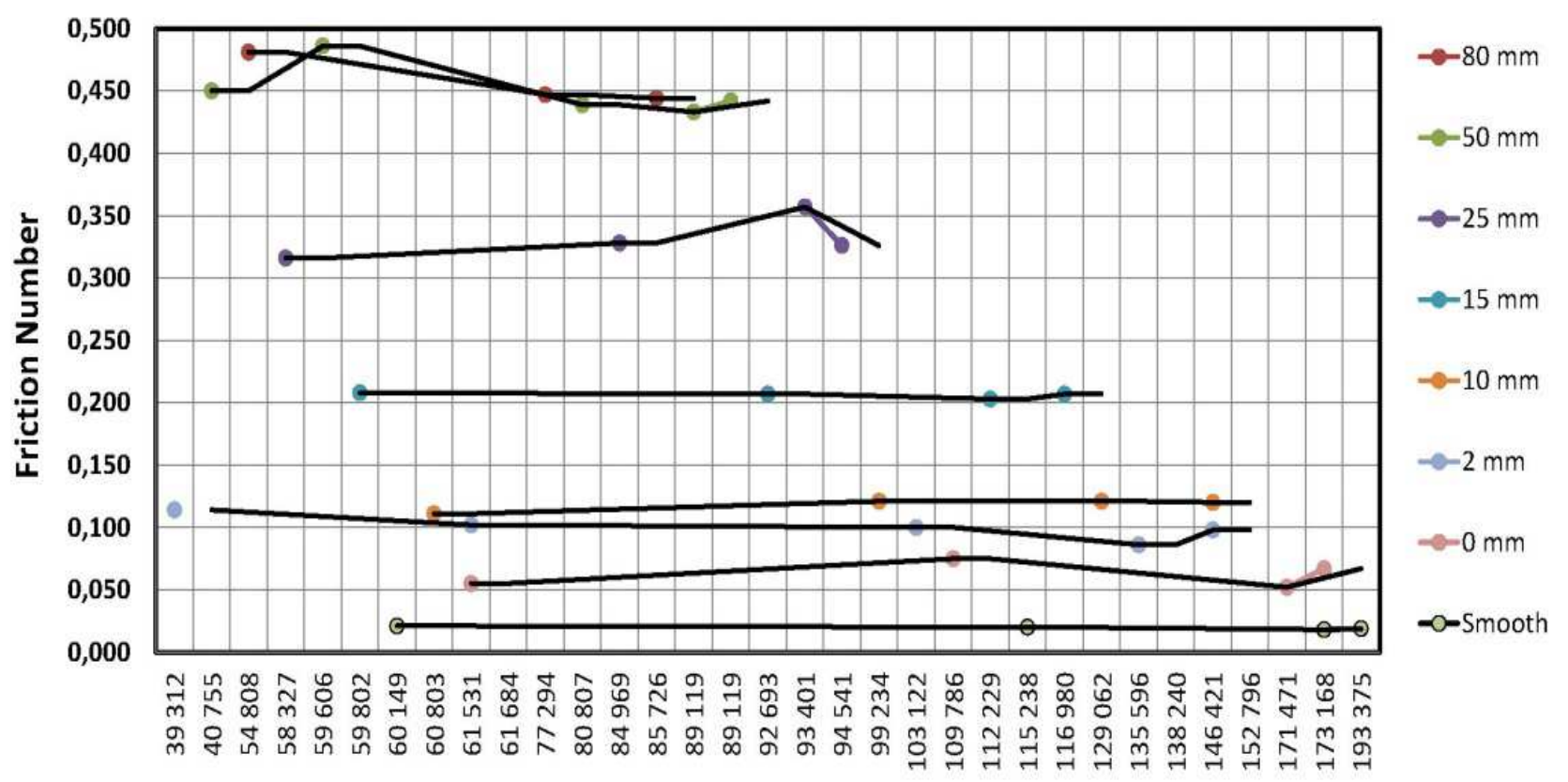

Reynolds Number

Figure 3. Friction number for various hair lengths of the carpet lining the test pipe. 


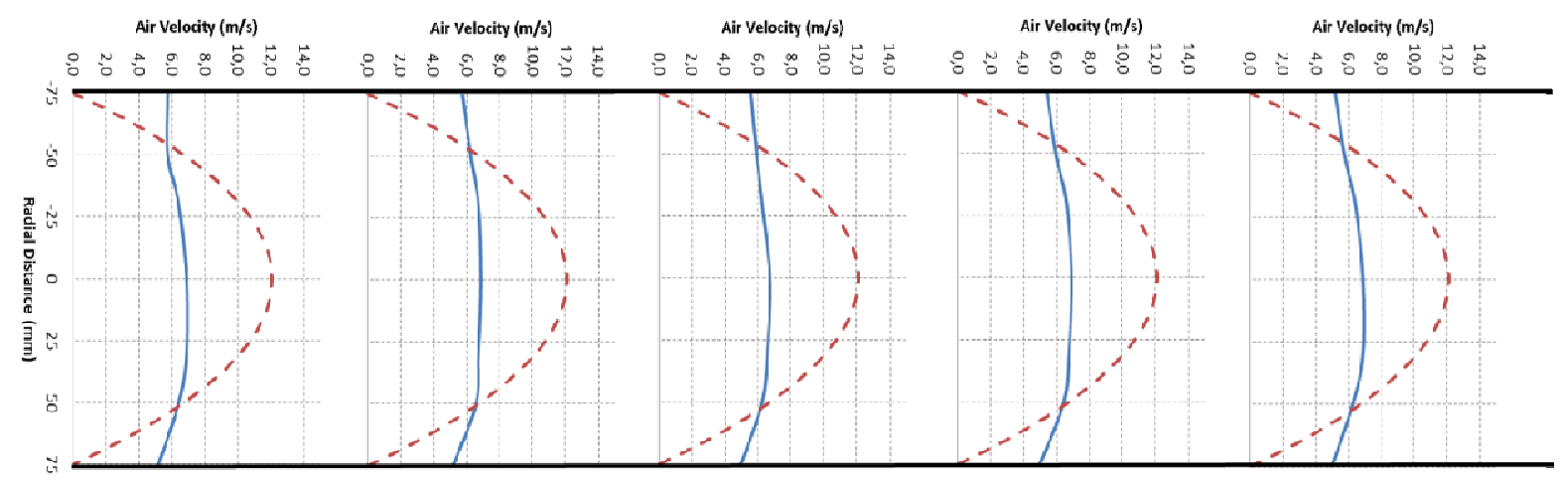

Case: 1:4, Re=60149, Smooth Pipe (no hair), Velocity profiles at 1.0, 2.0, 3.0, 4.0, $5.0 \mathrm{~m}$ from pipe entrance

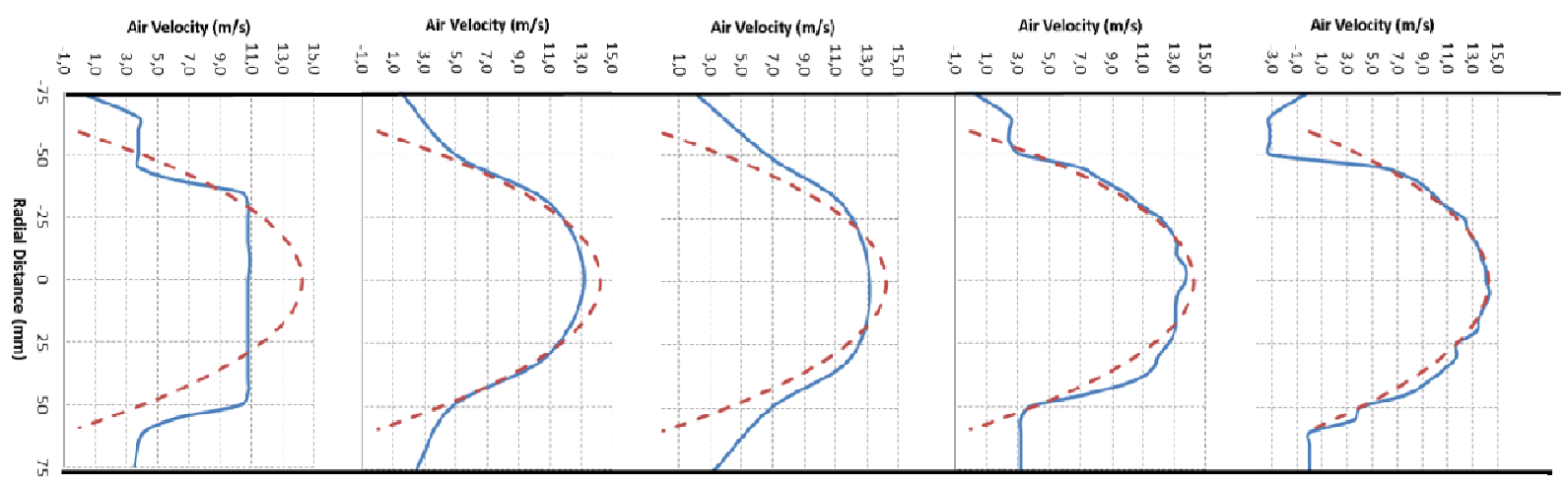

Case: $2: 4, \mathrm{Re}=55737$, Hair $=80 \mathrm{~mm}$, Velocity profiles at $0.15,1.0,3.0,4.0,5.0 \mathrm{~m}$ from pipe entrance

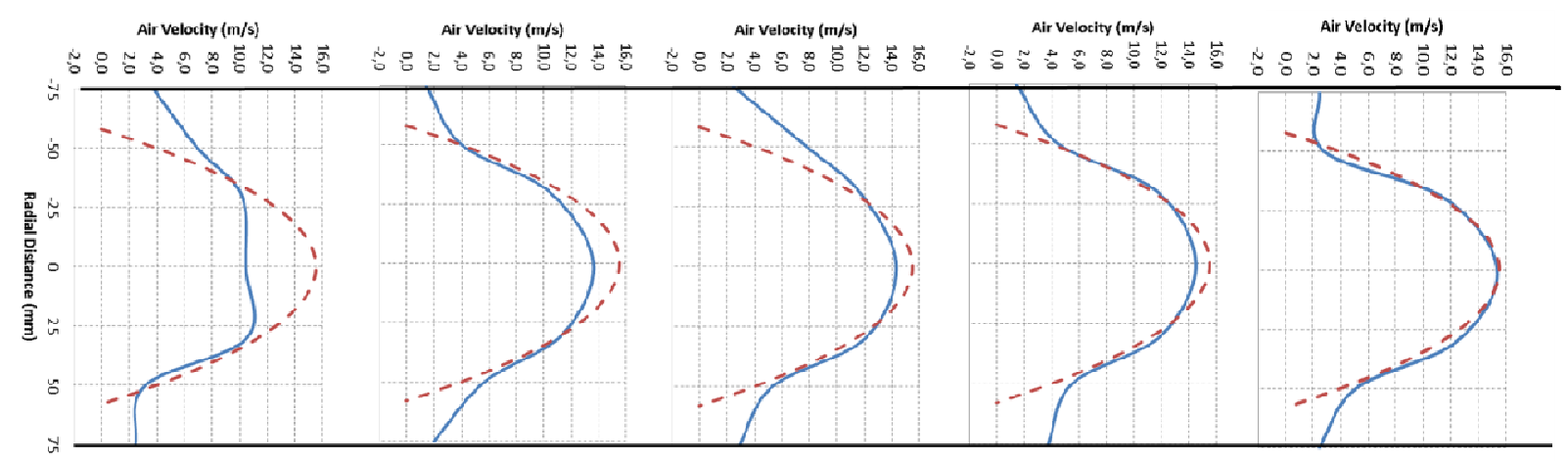

Case: $3: 4, \mathrm{Re}=59606$, Hair $=50 \mathrm{~mm}$, Velocity profiles at $0.15,2.0,4.0,4.5,5.0 \mathrm{~m}$ from pipe entrance

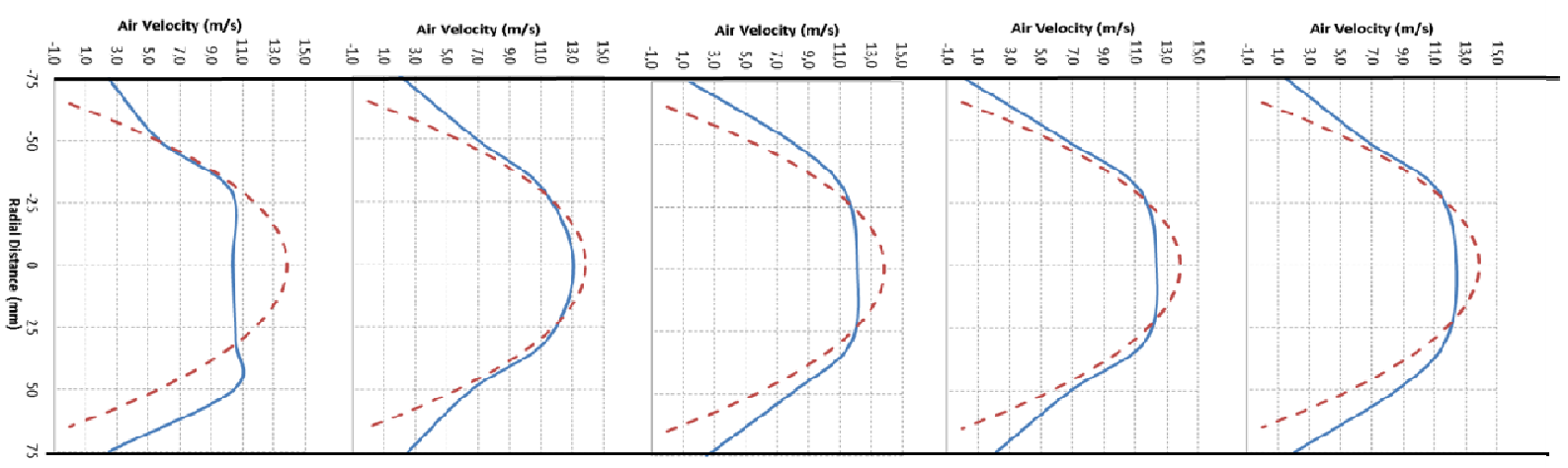

Case: 4:4, $\mathrm{Re}=59673$, Hair $=25 \mathrm{~mm}$, Velocity profiles at $0.15,2.0,4.5,4.8,5.0 \mathrm{~m}$ from pipe entrance

Figure 4a. Profiles of measured air velocity (solid line) and the ideal laminar velocity profile (broken line) at different sections along the pipe. Each case represents different Re numbers and hair lengths of the polyester carpet that is lining the pipe. The 8 cases presented in here are all for air flows with Re $\sim 60000$. 


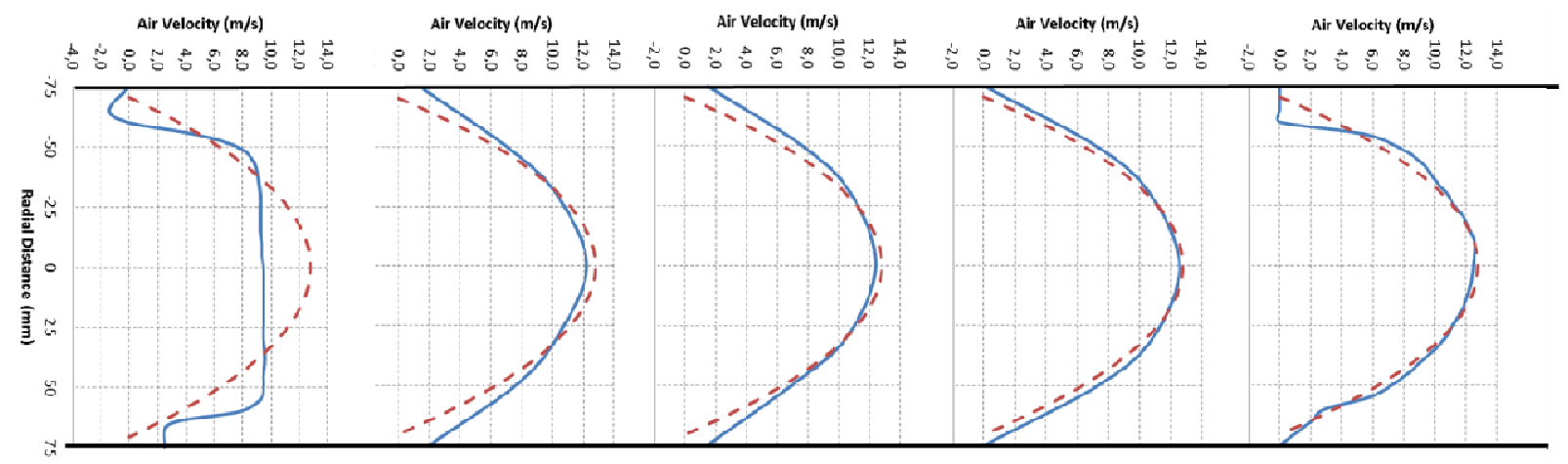

Case: 5:4, Re $=59802$, Hair $=15 \mathrm{~mm}$, Velocity profiles at $0.15,2.0,4.7,4.8,5.0 \mathrm{~m}$ from pipe entrance

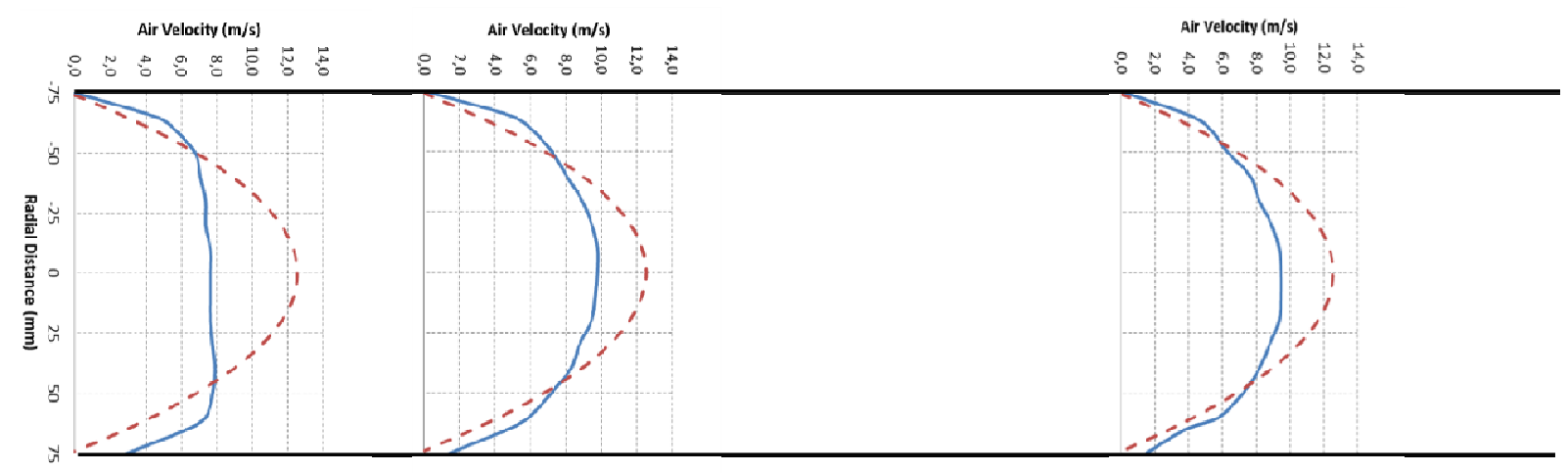

Case: 6:4, $\mathrm{Re}=60229$, Hair $=10 \mathrm{~mm}$, Velocity profiles at $0.15,2.0,5.0 \mathrm{~m}$ from pipe entrance

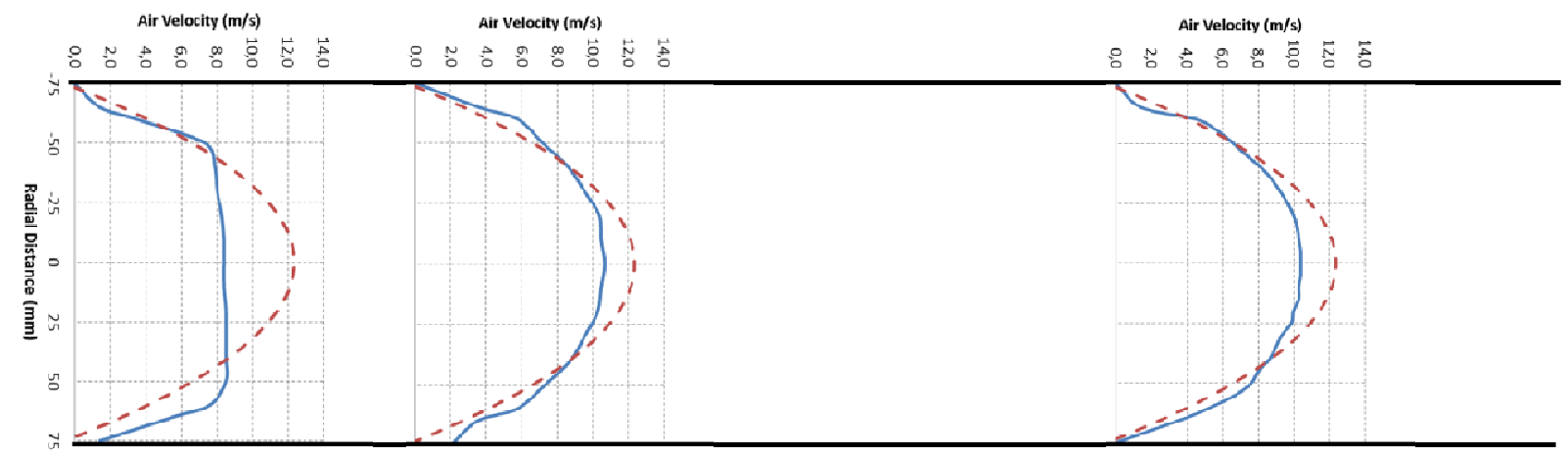

Case: 7:4, $\mathrm{Re}=61531$, Hair $=2 \mathrm{~mm}$, Velocity profiles at $0.15,2.0,5.0 \mathrm{~m}$ from pipe entrance

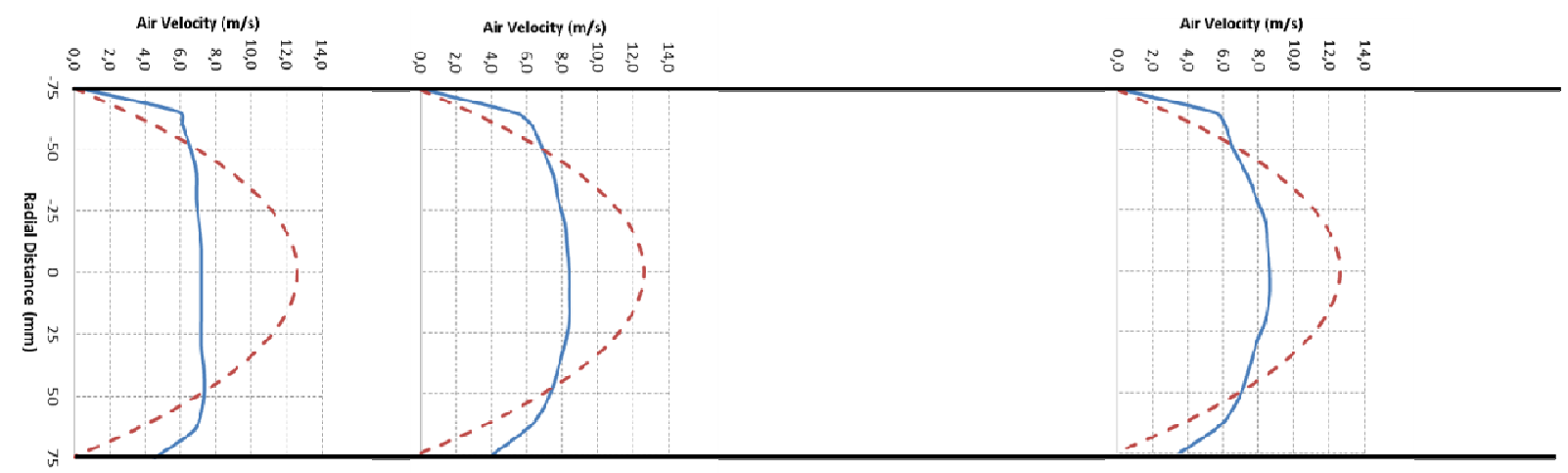

Case: $8: 4, \mathrm{Re}=62250$, Hair $=0 \mathrm{~mm}$ (only canvas), Velocity profiles at $0.15,2.0,5.0 \mathrm{~m}$ from pipe entrance

Figure 4b. Profiles of measured air velocity (solid line) and the ideal laminar velocity profile (broken line) at different sections along the pipe. Each case represents different Re numbers and hair lengths of the polyester carpet that is lining the pipe. The 8 cases presented in here are all for air flows with Re $\sim 60000$. 


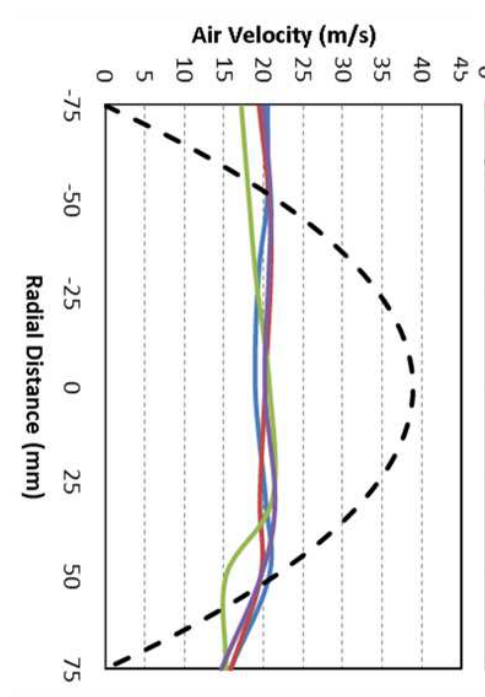

Case 1:1

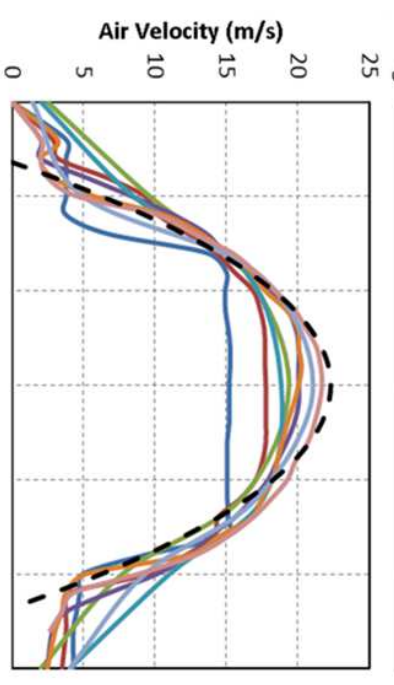

Case 2:1

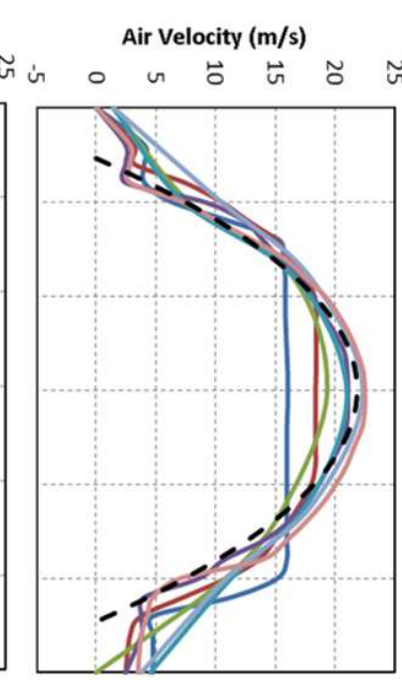

Case 3:1

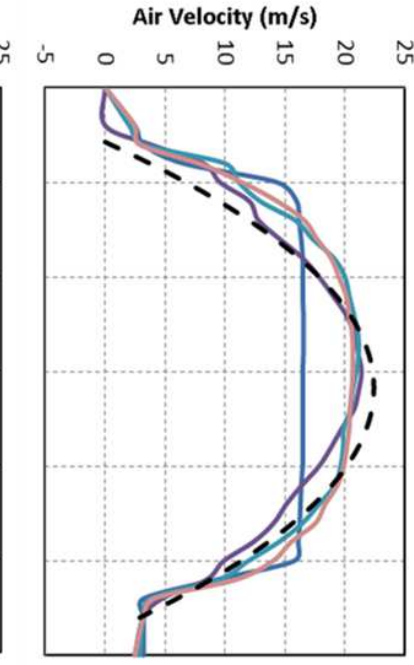

Case 4:1

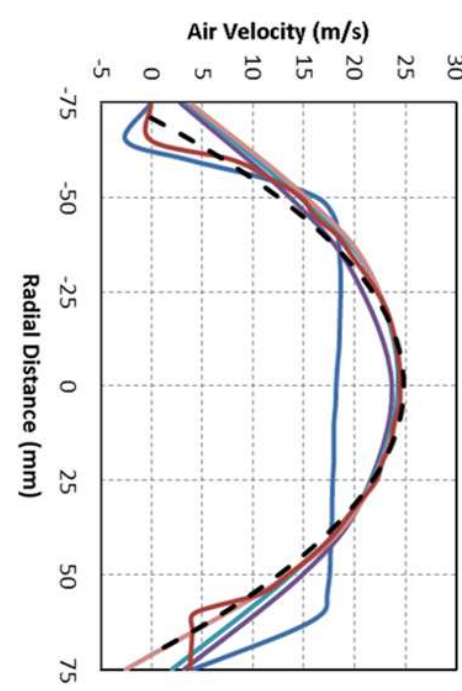

Case 5:1

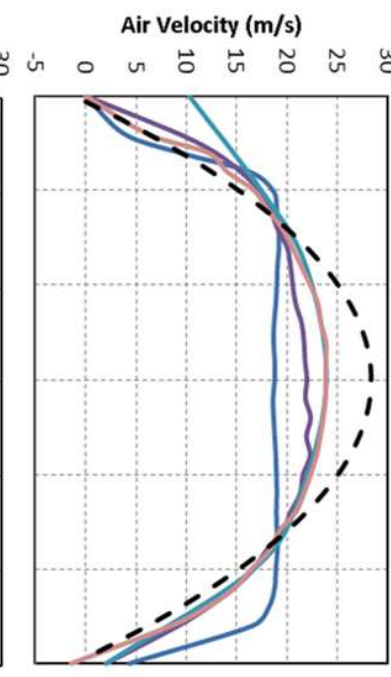

Case 6:1

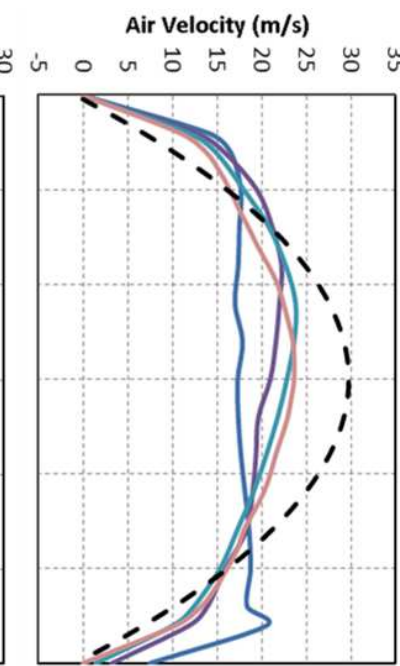

Case 7:1
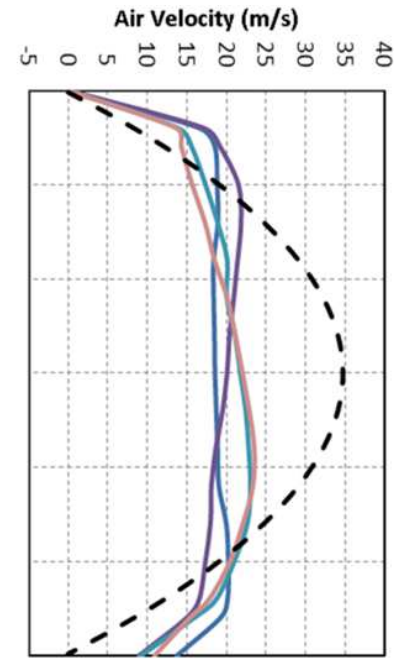

Case 8:1

Figure 5. The measured velocity profiles, which are tubulent at pipe entrance, are for some cases changed toward a laminar shape as it flows along the pipe.

Case 1 is for a smooth pipe while the pipe is lined with a hairy carpet in the other cases. The hair is cut shorter for for each case, starting with 80 mm in Case 2. Case 1:1, Smooth pipe, $\mathrm{Re}=193375$; Case 2:1, Hair length $=80 \mathrm{~mm}, \mathrm{Re}=85726$; Case 3:1, Hair length $=50 \mathrm{~mm}, \mathrm{Re}=89119 ;$ Case 4:1, Hair length $=25 \mathrm{~mm}, \mathrm{Re}$ $=94541$; Case 5:1, Hair length $=15 \mathrm{~mm}, \mathrm{Re}=116980$; Case 6:1, Hair length $=10 \mathrm{~mm}, \mathrm{Re}=138240 ;$ Case 7:1, Hair length = $2 \mathrm{~mm}$, Re = 146421; Case 8:1, Hair length $=0 \mathrm{~mm}, \mathrm{Re}=171471$.

\section{Conclusions}

Our objective was to investigate whether a pipe lined with a hairy soft carpet would laminarize air flows. The degree of laminarization was determined by the change of velocity profile along the test pipe. Varying flow rates were tested for each hair length before it was cut. It was shown that highly turbulent air flows $(\operatorname{Re}>100,000)$ seem to be laminarized by the hairy walls of the test pipe. If the hair of the wall mat is not too short the initially turbulent velocity profile changes towards a more laminar velocity profile. Some hair lengths worked better than others. An expected wave pattern occurred on the pipe wall. The evolving velocity profile is certainly less random than the typical turbulent profile at such high Re numbers. The friction number is considerably greater than that of an ideal laminar friction number. However, the ideal laminar friction should not be applicable at such high Re. The linear pressure drop along the pipe, in spite of the increasingly laminarized flow, indicates that that there is cost of energy in maintaining the laminarized profile. Performed measurements are available [17].

\section{Acknowledgement}

We are grateful for the encouraging interest in our work that at the time was shown by late Prof. Mårten T. Landahl (1927-1999) at Aeronautics and Astronautics, MIT, and 
Mechanical Engineering, KTH, Stockholm. We acknowledge the careful work of Katrina Nordell in transferring the handwritten measurements into digital format.

\section{Nomenclature}

\begin{tabular}{|c|c|c|}
\hline A & cross sectional area of pipe & $\mathrm{m}^{2}$ \\
\hline $\mathrm{D}$ & pipe diameter & $\mathrm{M}$ \\
\hline $\mathrm{D}_{\mathrm{h}}$ & hydraulic diameter & $\mathrm{M}$ \\
\hline $\mathrm{E}$ & kinetic energy & $\mathrm{kg} \mathrm{m}^{2} \mathrm{~s}^{-2}$ \\
\hline g & gravitational constant & $\mathrm{m} \mathrm{s}^{-2}$ \\
\hline $\mathrm{H}$ & $\begin{array}{l}\text { height of displaced water (i.e. air } \\
\text { pressure in m water column) }\end{array}$ & $\mathrm{M}$ \\
\hline $\mathrm{L}$ & pipe length & $\mathrm{M}$ \\
\hline$\lambda$ & friction number & - \\
\hline $\mathrm{m}$ & mass & $\mathrm{kg}$ \\
\hline $\mathrm{m}_{\mathrm{d}}$ & mass of displaced water & $\mathrm{kg}$ \\
\hline$v$ & dynamic viscosity & $\mathrm{m}^{2} \mathrm{~s}^{-1}$ \\
\hline$\Delta \mathrm{p}$ & drop in static pressure & $\mathrm{Pa}$ \\
\hline$P_{d}$ & dynamic pressure & $\mathrm{Pa}$ \\
\hline $\mathrm{P}_{\mathrm{s}}$ & static pressure & $\mathrm{Pa}$ \\
\hline$P_{t}$ & total pressure & $\mathrm{Pa}$ \\
\hline Q & flow rate & $\mathrm{m}^{3} \mathrm{~s}^{-1}$ \\
\hline$\rho$ & flow density & $\mathrm{kg} \mathrm{m}^{-3}$ \\
\hline$\rho_{\mathrm{a}}$ & density of air & $\mathrm{kg} \mathrm{m}^{-3}$ \\
\hline$\rho_{\mathrm{w}}$ & density of water & $\mathrm{kg} \mathrm{m}^{-3}$ \\
\hline $\mathrm{R}$ & radius of pipe & $\mathrm{m}$ \\
\hline $\mathrm{r}$ & radial distance & $\mathrm{m}$ \\
\hline $\operatorname{Re}$ & Reynolds Number & - \\
\hline $\mathrm{u}_{\text {mean }}$ & mean flow velocity & $\mathrm{m} \mathrm{s}^{-1}$ \\
\hline $\mathrm{u}$ & flow velocity & $\mathrm{m} \mathrm{s}^{-1}$ \\
\hline $\mathrm{u}_{\max }$ & maximum flow velocity & $\mathrm{m} \mathrm{s}^{-1}$ \\
\hline$\dot{v}$ & volume flow rate & $\mathrm{m}^{3} \mathrm{~s}^{-1}$ \\
\hline
\end{tabular}

\section{References}

[1] Maxwell J.C. A Treatise on Electricity and Magnetism, 3rd ed., vol. 2. Oxford: Clarendon, 1892, pp.68-73.

[2] Pennel W. T., Eckert E. R. G., Sparrow E. M. Laminarization of turbulent pipe flow by fluid injection. J. Fluid Mech. (1972), vol. 52, part 3, pp. 451-464

[3] Zubkov V.G. Numerical study of laminarization effects in turbulent boundary layers of accelerated flows. Zhurnal Prikladnoi Mekhaniki I Teknicheskoi Fiziki, No 2, pp. 71-78, March-April, 1985. 0021-8944/85/2602-0215809.50, Plenum Publishing Corporation.
[4] Riasi, A., Nourbakhsh M., Raisee M. (2009). Unsteady turbulent pipe flow due to water hammer using $\mathrm{k}-\theta$ turbulence model. J. Hydr. Res. 47:4, 429-437. DOI:10.1080/00221686.2009.9522018

[5] Cardoso A.H., Graf W.H., Gust G. (1991) Steady gradually accelerating flow in a smooth open channel, J. Hydr. Res. 29:4, 525-543, DOI:10.1080/00221689109498972

[6] Cederwall K., Sellgren A. (1973). Polymeradditiv (Polymer Additive), Chalmers University of Technology, Gothenburg, Sweden. (In Swedish)

[7] Toms, B.A., (1948). Some observations on the flow of linear polymer solutions through straight tubes at large Reynolds numbers. Proc. 1st International Congress on Rheology, Vol. 2, North Holland Publishing Co., Amsterdam, Holland, p. 134.

[8] Afzelius B. (1976). The role of cilia in man. Elsevier/North-Holland Biomedical Press.

[9] Wu T.Y., Brokaw, C. J., Brennen, C. (1975). Swimming and Flying in Nature, Vol 2, p 939-952. Plenum Press, New York and London.

[10] Graham RN. (1934). The silent flight of owl. J of Royal Aeronautic Soc., pp. 837-843.

[11] Gruschka H.D., Borchers I. U., Coble J. G. (1971). Aerodynamic Noise produced by a Gliding Owl. Nature 233, 409 - 411 (08 October 1971); doi:10.1038/233409a0

[12] Thorpe W.H., Griffin D.R. (1962). The lack of ultrasonic components in flight noise of owl compared with other birds. Ibis 104:256-257.

[13] Lindblad J. (1973). I Ugglemarker (Owl Land), Bonniers, Stockholm, Sweden. 211 p. ISBN 91-0-037720-1 (In Swedish)

[14] Gray, J. (1936) Studies in animal locomotion VI. The propulsive powers of the dolphin. J. Exp. Biol. 13: 192-199.

[15] Norberg R.Å. (1975). Skull asymmetry, ear structure and function, and auditory localization in Tengmalm's owl, Aegolius funereus (L.), with aspects on the evolution of ear asymmetry among owls. Doctoral Thesis, Gothenburg University.

[16] Cousteau J.Y., Diolé P. (1975) Dolphins. Doubleday \& Company Inc. Garden City, New York.

[17] Nordell B., Gawelin R. (2014). Laminarization of Highly Turbulent Air Flow. Measurements in Excel format. http://dx.doi.org/10.5281/zenodo.14784)

[18] Nilsson R., Nordell B., (1979). Experiments in reducing turbulence in pipe flow. (Försök med turbulensminskning). MSc. Thesis 1979:040E, Div. Water Res. Eng., Luleå Univ. of Techn., Sweden. (In Swedish) http://pure.ltu.se/portal/files/91305512/1979_040E.pdf

[19] NVG (1974). Nordic Ventilation Group, Guidelines for air flow rate determination. Swedish Council for Building Research, R51:1974. (In Swedish)

[20] Batchelor G.K. (1967). An Introduction to Fluid Dynamics. Cambridge University Press, U.K. 